[Transaction ]

\title{
Korean Wrapping Cloths as a Decorative Art
}

\author{
Soon-young Kim ${ }^{\dagger}$ \\ Dept. of History of Design, Royal College of Art \\ Received August 26, 2009; Revised October 20, 2009; Accepted November 18, 2009 \\ 한국 보자기의 장식성 연구 \\ 김 순 영 \\ Dept. of History of Design, Royal College of Art \\ 접수일(2009년 8월 26일), 수정일(2009년 10월 20일), 게재확정일(2009년 11월 18일)
}

\begin{abstract}
This paper explores the use of Korean wrapping cloths (bojagi) in the late Joseon period and the types of decorations applied to them. Korean wrapping cloths called bojagi are pieces of cloths used by households of all social classes for practical purposes such as wrapping presents and covering food. In addition to the basic purposes, the making of bojagi was also an activity to express the down-to-earth wishes and the satisfaction of creation by the designer. With regard to the decorative feature of Korean wrapping cloths, five types of, patchwork, embroidered, painted, printed, and oiled-paper wrapping cloths, were examined. The patchwork wrapping cloths (jogakbo) show the frugality of Joseon women in addition to the well-developed composition skill of lines and colors. The embroidered wrapping cloths were prepared for special rituals and ceremonies such as weddings. Painted wrapping cloths were decorated with a Chinese-colors technique (called dangchae) or sometimes with black ink painting. For printed wrapping cloths, various sizes of woodblock printings and roller printings were used. Although monotone black ink was the main color applied to the printing, there was also wrapping cloths made from chintz having brilliant fast colors. Oiled-paper wrapping cloths called sikjibo were in use only for covering food. Cut-out work was employed to decorate it.
\end{abstract}

Key words: Patchwork wrapping cloths, Embroidered wrapping cloths, Painting technique, Printing technique, Cut-out work; 조각보, 수보, 회염, 인염, 오려내기 세공

\section{Introduction}

Korean wrapping cloths called bojagi are pieces of cloths used by Koreans for wrapping presents, covering food, storing clothing or bedding quilts, and protecting ornaments. Bojagi are still used for special purposes like weddings, although the usage of bojagi has been in decline since instant wrapping paper became available. Currently bojagi are being reevalu-

${ }^{\dagger}$ Corresponding author

E-mail: ksyo3@chol.com ated as a substitute for wrapping paper along with the recent trend to emphasize sustainable resources. Korean wrapping cloths (especially patchwork wrapping cloths, jogakbo) has received attention because of the idea of recycling as well as the creative aesthetics.

Recent researches on wrapping cloths have been conducted by specialists in the field of textile design, art history, and Korean studies. Most of them, including the leading authority on the subject, Huh Donghwa, have dealt with the aesthetic of wrapping cloths (Huh, 1988, 2003; Hyen, 1997; Kim, 2007; Kim, 2003; 
Lee, 1999; Noh, 2006). A couple of them talked about wrapping cloths in relation to the lifestyles of women (Lee, 2003) or techniques (Kim, 1998). However, these outcomes focused on patchwork wrapping cloths and embroidered wrapping cloths. This paper explains the various types of wrapping cloths in terms of a decorative expression, along with the understanding on the circumstances of the production of bojagi. This paper focuses on what types of wrapping cloths were used by Koreans, why they were made, and what kinds of decorations were applied to each type.

The decorative arts are defined as ornamental and functional works in ceramic, wood, glass, metal, and textiles. These are often categorized outside of the fine arts. The perceptions of wrapping cloths as a decorative art show a need to reevaluate the Korean decorative culture on fabric materials. It is understood that the inhabitants of the Joseon dynasty employed a humble attitude in regards to the decorative features shown in Korean dresses of the Joseon dynasty. However, the types of decorations shown in bojagi show a need to reconsider this notion.

This paper focused on the $19^{\text {th }}$ to the early $20^{\text {th }}$ century because most of the remaining Korean wrapping cloths were made in the late Joseon dynasty and the period of Japanese occupation. Ten volumes of catalogues on bojagi (most of which were published by the Museum of Korean Embroidery) and two silk bojagi objects held in the British Museum were used for this research. Some documentation, including

${ }^{『}$ Geongguk Daejeon (The National Code of the Joseon dynasty)』(King Seongjong, 1485/1985), 『Joseon Jaebong Jeonseo (Joseon Sewing Encyclopedia)』 (Kim, 1925/1997) and 『Joseon Yeosokko (Joseon women's customs)』(Yi, 1927/1986) were also referred to. Folk paintings by Kim, Jun-geun (who lived in the late $19^{\text {th }}$ to the early $20^{\text {th }}$ century) were examined to understand the circumstances in which bojagi were used.

\section{Literature Review}

\section{Definition and Type}

Considering the literal meaning and pronunciation of Chinese characters, three kinds of definitions that refer to bojagi can be found. The first definition is 'to wrap' or a 'baby wrapper'. The pronunciations are 'bok', 'bo', or 'boja' (Huh, 1988). In addition, Koreans related bojagi with 'the wrapping of happiness' because the pronunciation of one of the Chinese characters referring to bojagi was the same as 'bok' meaning happiness (Dictionary of Korean myths and symbols, 2006; Kang, 1997). The last definition is 'wrapping clothing' (Huh, 1988). The public regarded it as a 'dress', because both of them had similar functions and meaning. In terms of function, a wrapping cloth is for wrapping objects and a dress is for wrapping the human body. In terms of expression of courtesy, both of them also had commonality. In the Joseon society, dresses were regarded as an important means to express politeness towards others that demonstrated a need to be smart and clean outside of home. Bojagi was also one of the agents to express sincerity towards the receiver through the action of wrapping.

Bojagi can be categorized into various types according to the user, the purpose, materials used, method of construction, and decoration. Of these criteria, 'decoration' was selected as the main factor to separate bojagi into several types, because the decorative aspect played an important role in finding some of the lost traditions in the decoration of fabric materials. Depending on the type of 'decoration', bojagi was categorized into five kinds: patchwork, embroidered, painted, printed, and cut-out work oiled-paper wrapping cloths.

\section{Reasons of the Making of Bojagi}

There exists a need to discuss under what circumstances the bojagi was produced prior the examination of the decorative features of each type of bojagi. Three aspects were examined in regards to the reasons of the making of a bojagi. The first reason was the 'practical purpose', the second was related to 'down-to-earth wishes', and the final was the 'amusement of creation'. The 'practical purpose' and 'downto-earth wishes' were an 'intended' and 'conscious' activity that show a similarity. However, the 'amusement of creation' is likely a 'subconscious' activity (Fig. 1). 


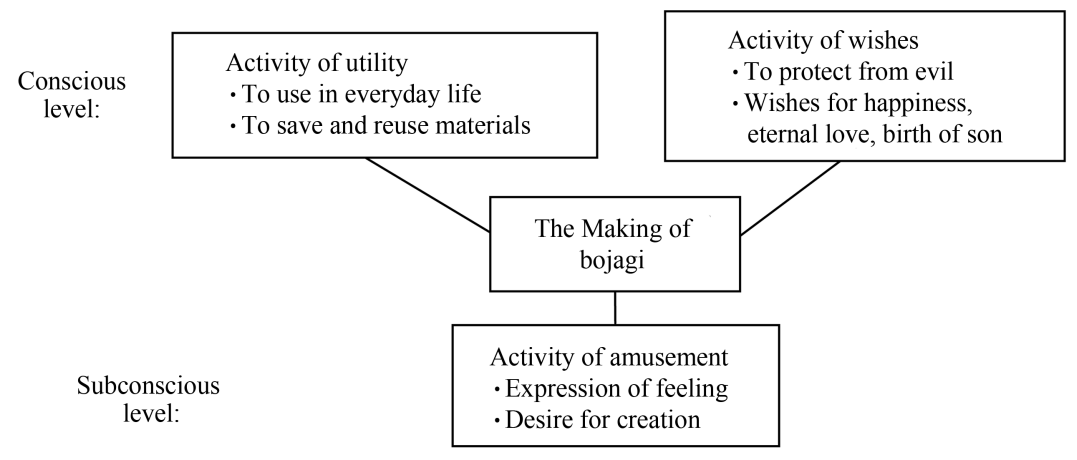

Fig. 1. Reasons of the making of bojagi.

Considering the 'practical' purpose, bojagi was used to wrap presents, cover food, store fabric, look after bedding quilts, and to protect something precious in everyday life. Some folk paintings by Kim, Jun-geon clearly revealed the practical usages of bojagi. His paintings show food baskets or wooden trays covered by bojagi, and peddlers carrying wares wrapped in bojagi (Fig. 2) (Korea Culture and Content Agency et al., 2004).

Another practical reason (especially in patchwork wrapping cloths) can be found in an intention to save material or reuse old dresses as well. Spinning and weaving were the regular tasks performed by women of all classes (Lee, 2003). The whole process of weaving was time-consuming and women could not dispose of any small pieces of cloth (Kim, 2003). Based

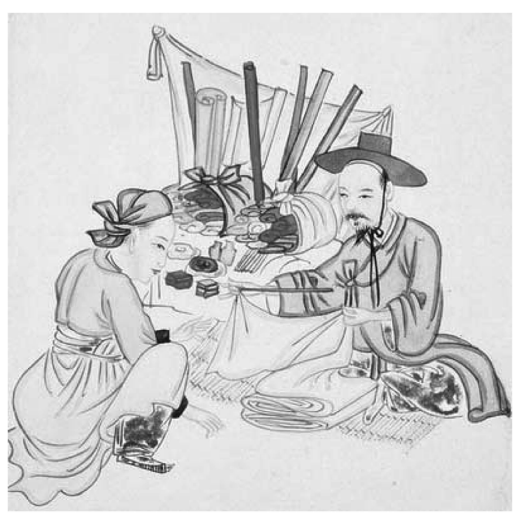

Fig. 2. Clothes peddler.

From The National Research Institute of Cultural Properties. (1999). Korean cultural properties of the Guimet national museum of Asian art, France. p. 114. on Confucianism thought, needlework and the frugal habit of saving material were regarded as virtues that women had to practice.

Another reason for the making of bojagi was related to 'down-to-earth wishes'. Makers of bojagi seem to have been aware of the traditional symbols of motifs, shapes, and colors. They pursued a series of symbolic meanings such as happiness, conjugal love, longevity, and the birth of son through constructing a bojagi. These beliefs are why many wrapping cloths were designed for weddings. Some paintings by Kim, Jun-geun display a goose and wedding presents wrapped in bojagi (Fig. 3) (Korea Culture and Content Agency et al., 2004). The wooden goose had been used for wedding ceremonies as a symbol

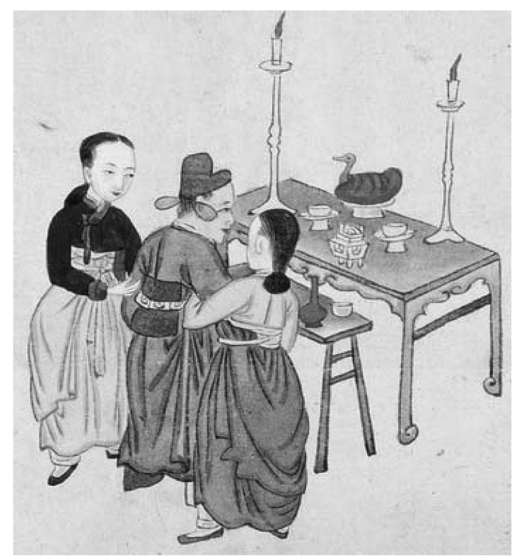

Fig. 3. Giving a goose.

From The National Research Institute of Cultural Properties. (1999). Korean cultural properties of the Guimet national museum of Asian art, France. p. 122. 
of eternal love. Blue and red colors were mainly employed for wrapping wedding presents because they were male and female symbols from the ancient philosophy of yin-yang.

The triangular shapes were thought to protect from evil (Hyen, 1997). This superstition is why triangular shapes of decoration were employed for the edges of the bojagi <Fig. 5>, and for the decoration of children's dresses in many cases. This symbol related to the protection from evil is not confined to the Korea peninsula. One of the pillow-ends used in the Shanxi province of China, reveals a similar way of triangular decoration on each edge (Fig. 7). The pillow-end was filled with embroidered and appliquéd design to represent the belief that children could live longer and be less vulnerable to evil spirits (Berliner, 1986). In addition, in consideration of the effort of stitching, the makers could believe that blessings and happiness could be accumulated with each stitch.

The last reason of the making of bojagi is related to the more 'subconscious' aspect, which was a psychological aspect. The status of women was subservient under the strict moral code of the Confucianism that governed Joseon society. They had to follow the instructions of their father or husband; in addition, their social lives were confined within many barriers (Yi, 2003). For instance, according to the ${ }^{\circledR}$ Geongguk Daejeon (The National Code of the Joseon dynasty)』 (King Seongjong, 1485/1985), which was the basic code that was applied to the Joseon dynasty contained a regulation as follows: the Yangban class of women were prohibited from social gatherings outside, in the mountains, or within the city walls. Another document, ${ }^{『}$ Joseon Yeosokko (Joseon women's customs)』(Yi, 1927/1986) says, "the so-called naeoebeup, the code of ethics between male and female, according to which the woman was not supposed to see men other than her own immediate family members, dictated that the woman stay in the inner court... when she went out, she had to ride in a covered palanquin in order not to be seen by other men." Also, one of the most famous Joseon philosophers, Yi, Hwang stated (as cited in Yi, 2003), "ladies should be able to compose poems, do calligraphy, read history, lesser learning, and the Admonition to Ladies, and be able to recognize the names of kings and ancestors. However, excessive skill in writing or brilliancy in poetry is rather like a courtesan, kinyeo, and not what is expected of well-born ladies."

These statements imply that the activities of women were confined to the home (especially to the inner court of the household) and that a liberal humanist expression of emotion was restricted. Inferred is that women might need a means to express emotions and creative talents and that this expression would have been through needlework because it was accepted of women as a virtue and a positive desirable task.

\section{Characteristics of Patchwork Wrapping Cloths, Jogakbo}

Patchwork wrapping cloths (jogakbo) are the most prominent of Korean wrapping cloths, which were used not by the royal court, but by citizens. Jogakbo was composed with many lines and colors. It was categorized into three types according to the arrangement of lines and colors.

\section{The Composition of Regular Shapes and Various Colors}

The first type is the composition of regular shapes and various colors made mostly of silk. <Fig. 4> is a drawing from a sewing book written by Kim (1925/ 1997). The author explained how to compose jogakbo in the section of 'the making of colorful silk jogakbo'. In order to make silk jogakbo, the most important skill was the 'color arrangement'. The drawing in <Fig. 4> represents the basic method of the color arrangement to make a jogakbo as follows; the first thing is to prepare small pieces of the same-sized square-shaped cloths, then to arrange the same color pieces in diagonal pattern. <Fig. 5> is an example of jogakbo having a similar way of arrangement to the drawing shown in <Fig. 4>. However, women were not satisfied with such a basic way. Many remaining wrapping cloths prove that women tried to deviate from the basic rule as sewing skills improved. In some jogakbo, various colors of small flowers were embroidered as an additional decoration. Sometimes, 


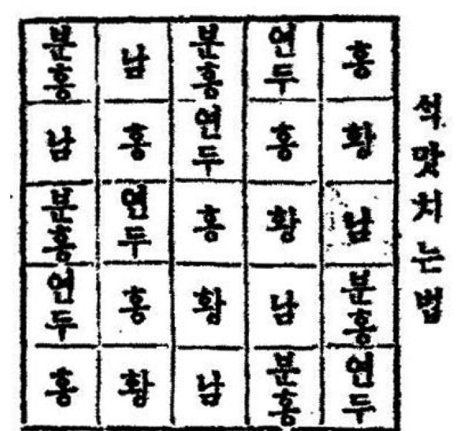

Fig. 4. The making of colorful silk jogakbo. From Kim, S. D. (1925/1997). Joseon Jaebong Jeonseo (Joseon Sewing Encyclopedia). p. 100.

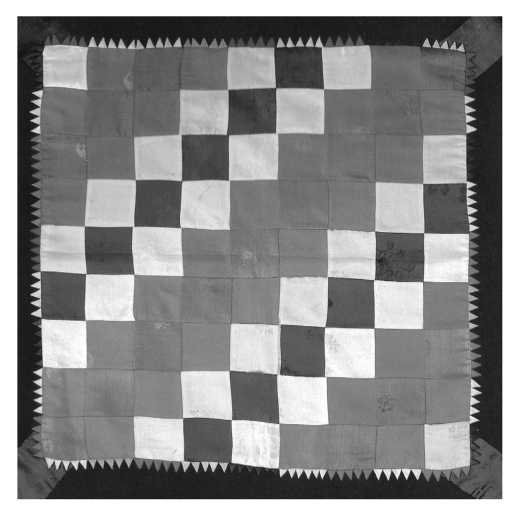

Fig. 5. Patchwork wrapping cloth made from silk, held in the Museum of Korean Embroidery.

From Huh, D. H. (1988). The wonder cloth. p. 65.

colorful thread different from the color of the background was in use for sewing. This way of distinct stitches might have been a 'show-off' of the sewing skill of the designer as well as a 'decoration' (Fig. 6). The similar method of stitches was also found in the pillow-ends used in Shanxi province, China (Fig. 7).

Although most of jogakbo were composed of straight lines, there were some examples composed with round shapes. An example of the combination of a regular round shape and various colors is shown in <Fig. 8>. Each circle is interlocking with four nearby circles. Therefore, the shapes seem to be a connection of circles or a connection of flowers having four petals. It is notable that the same motif was also found in the stoneware made in the Goryeo dynasty that was exhibited at the Korea gallery of

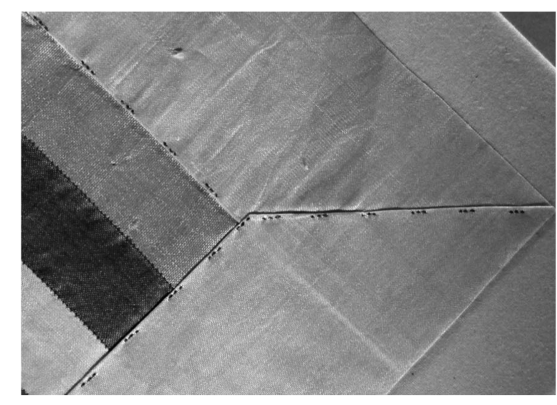

Fig. 6. Patchwork wrapping cloth (part) made from silk, held in the British Museum.

Photographed by author (Feb. 24, 2009.)

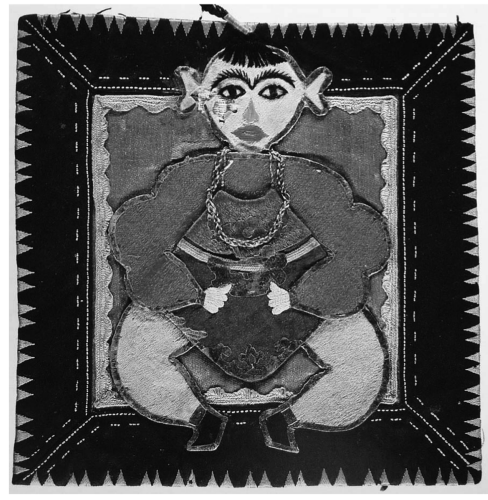

Fig. 7. Pillow-end used in Shanxi province. From Berliner, N. Z. (1986). Chinese folk art. p. 177.

the British Museum. The interlocking round pattern was called the 'yeoyiju pattern'. Yeoyiju is an imaginary bead found in Buddhism that was believed to bring the owner anything wished for. It is inferred that women sometimes adopted religious motifs for a jogakbo. The interlocking round pattern was also shown in the baby carrier (sling) used by the ethnic Bai in Yunnan province, China (Fig. 9). The Bai dresses have been developed under the influence of the Yi, the Naxi, and Tibetans living in proximity (National Museum of History, 2000). The interlocking round shape seems to have been common in the area where Buddhism was popular. In Buddhism, a round shape is an important symbol and Mandara (a Buddhist term) means perfect universe or round shape, that has a healing ability (Noh, 2006). 


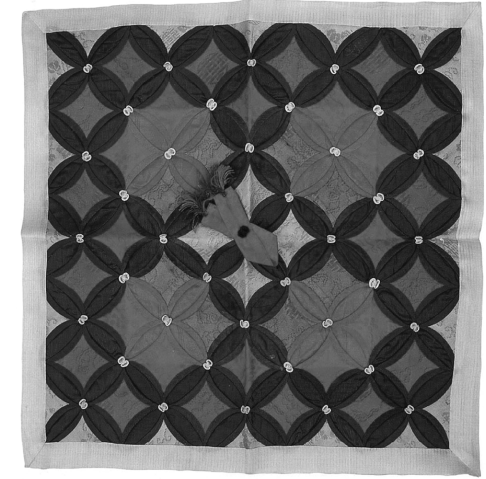

Fig. 8. Patchwork wrapping cloth made from silk, held in the Museum of Korean Embroidery.

From Huh, D. H., \& Park, Y. S. (1988). Crafts of the inner court. p. 130.

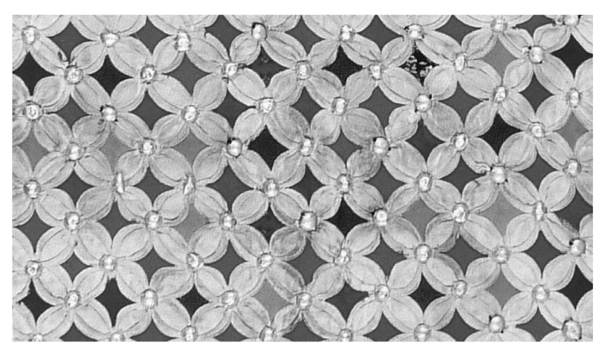

Fig. 9. Embroidered baby wrapper (part).

From National Museum of History. (2000). Costumes and accessories of Chinese minorities. p. 267.

\section{The Composition of Irregular Shapes and Monochrome Color}

The second type is the composition of irregular shapes and monochrome color. Although one or two point colors were sometimes used on it, this type of jogakbo was almost completely comprised of a monotone color and was mainly made of ramie. In ${ }^{『}$ Joseon Jaebong Jeonseo (Joseon Sewing Encyclopedia)』by $\operatorname{Kim}(1925 / 1997)$, there was another section describing how to connect hemp or ramie patches. However, there was no mention of the color arrangement in this part. Instead, the drawing was focused on how to achieve the whole shape by connecting each piece (Fig. 10). It is important to understand why the author, Kim, focused on 'the shape of jogakbo' in the section on 'hemp (or ramie)' and why she focused on the 'color composition of jogakbo' in the part on 'silk'.
These different tendencies are also seen in the remaining jogakbo and might have been related to 'dyeing efficiency'. Animal fibers such as silk tend to absorb dye ingredients more readily rather than vegetable fibers like ramie or hemp and women could have obtained diverse colors in silk materials than from ramie or hemp fabrics.

Sometimes, in order to avoid simplicity, one or two point colors were used for this type of jogakbo and $<$ Fig. 11> is one of these examples. The creative sense and well-developed composition skill of the maker are shown from the way of plane division. The maker positioned small blue pieces in the centre and red pieces in each corner as point colors.

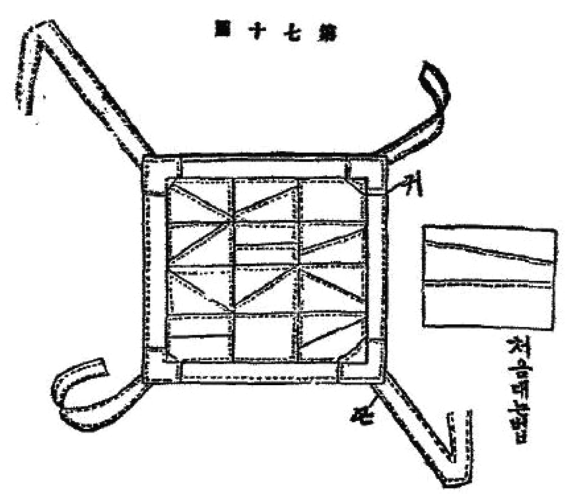

Fig. 10. The making of hemp or ramie jogakbo. From Kim, S. D. (1925/1997). Joseon Jaebong Jeonseo (Joseon Sewing Encyclopedia). p. 99.

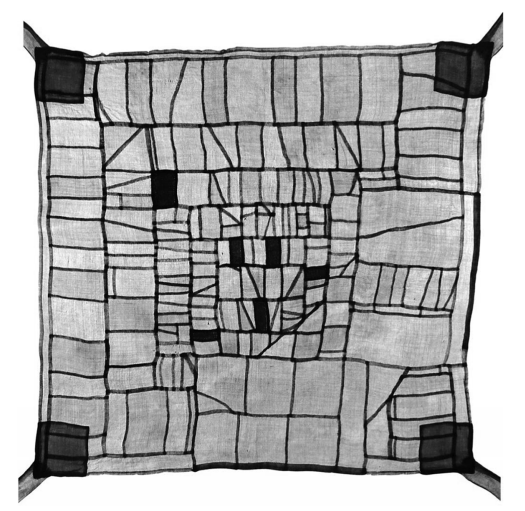

Fig. 11. Patchwork wrapping cloth made from ramie, held in the Museum of Korean Embroidery. From National Museum of Korea. (1988). Hangukui Mi (Beauty of Korea). p. 108. 


\section{The Composition of Irregular Shapes and Various Colors}

The last type is the composition of 'irregular shapes and various colors'. This type of composition displays more advanced skills in the arrangement of many colorful pieces. The last type has been thought to be the most representative of Korean wrapping cloths because of the sophisticated abstraction.

Five fundamental colors that consisted of, red, blue, yellow, white, and black were used in jogakbo. These colors were regarded as the most fundamental components that comprise the universe. The adoption of these five colors had been treated as a 'good' and 'desirable' attitude. However, many remaining jogakbo reveals that women also employed other colors in addition to the five basic colors (Fig. 12). The additional colors (pink, green, pale blue, purple, and brown) were called the five secondary colors. Under Confucianism, the use of these five secondary colors was thought to be an 'undesirable' habit that charmed the eyes and mind (Kim, 2005). However, women did not hesitate to put these colors to good use for the profusion of color expression. The diverse pure colors shown in many jogakbo imply that the inhabitants of the Joseon dynasty would enjoy special colors in their everyday lives.

A patchwork technique was employed by western African people (Fig. 13). The School of Oriental and African Studies, University of London, has shown interest in the difference between Korean patchwork wrapping cloths and African wrappers. A wrapper is

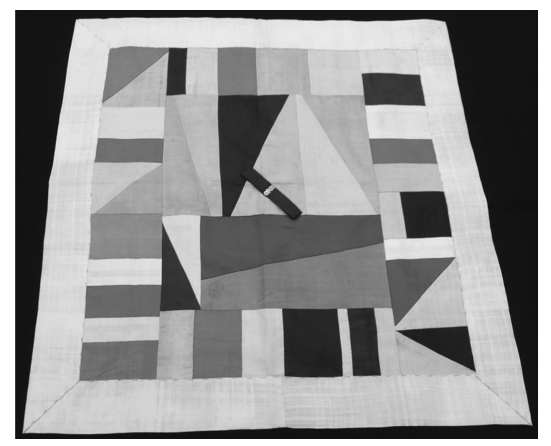

Fig. 12. Patchwork wrapping cloth made from silk, held in the British Museum.

Photographed by author (Feb. 24, 2009.)

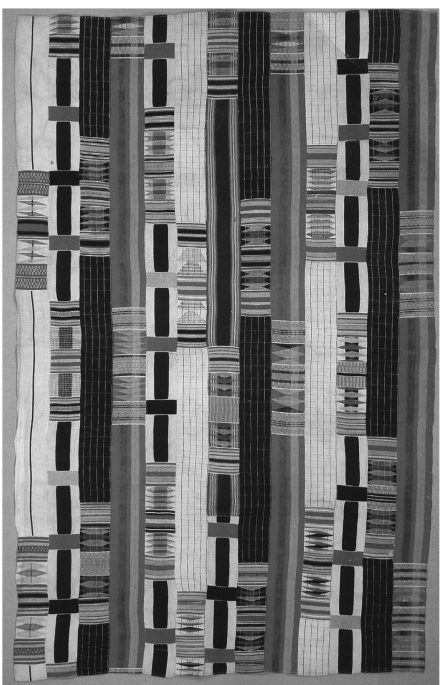

Fig. 13. Wrapper worn by Asante people. From Gilfoy, P. S. (1987). Patterns of life. p. 83.

a dress item for wrapping up the body mostly worn by western African people, such as in Ghana (Gilfoy, 1987). Although western African wrappers were composed by sewing separate pieces of cloths together, the methods of creating and the final beauty looked very different from a Korean jogakbo. First, while an African wrapper was composed of several strips of new cloths, a jogakbo consisted of many small pieces of scrap material. Another different factor was how to create the pattern. Whereas the pattern of each strip of the wrapper was made in the process of weaving, the pattern of the jogakbo was created only by sewing the small pieces of cloths together. Therefore, the wrapper represents a 'stylized aesthetic' and the jogakbo reveals a more 'random creativity'.

\section{Characteristics of Embroidered Wrapping Cloths, Subo}

Although embroidery was in use for many fabric items such as wall screens, cushions, and ceremonial dresses at court, embroidered wrapping cloths used at court were rarely found. Most of remaining embroidered wrapping cloths are known to have been especially used by the inhabitants of Gangwon province (Huh, 1988). Subo was prepared for auspicious cere- 
monies such as wedding.

Four kinds of features were found in subo in regards to the expression of embroidery motifs. The fist feature was the 'simplification of the objects'. Unlike court embroidery, the subo used in Gangwon province revealed a less descriptive and a more simplified aesthetic (Fig. 14), (Fig. 16). The second feature was related to 'viewpoint'. Two kinds of viewpoints were observed; one was viewpoint 'from the front', the other was 'from the top' (Huh, 1988). The tree shown in $\langle$ Fig. 14> is stretching its branches outwards. The tree is symmetrical by the vertical truck at the centre and leaves are hanging on its branches. However, a careful examination of the leaves shows that the viewpoint of the leaves is different from those of the trunk and branches. Confusion can exist about whether the whole tree was viewed from the front or the top. This strange viewpoint that combined two different kinds of viewpoints was also found in one of the $19^{\text {th }}$ century Korean folk screen paintings. The screen shown in $\langle$ Fig. 15> reveals that the trunk was viewed from the front and the leaves were viewed from the top. This indicates that some expressive forms of motifs applied to subo might have been influenced by other decorative arts.

The next feature was the compact composition. The surface of subo tended to be filled with many branches and leaves almost without any surplus space (Fig. 14), (Fig. 16). The final feature was a rhythmi-

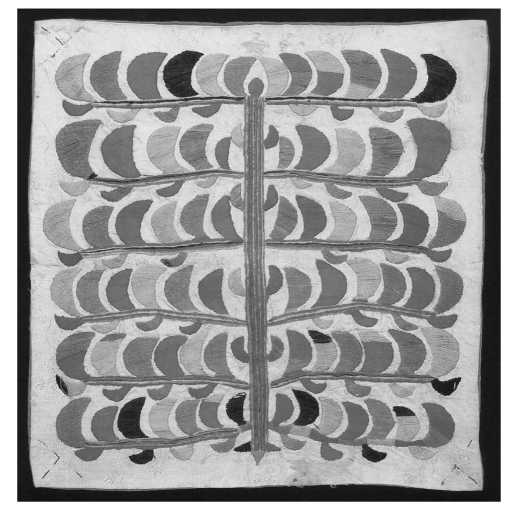

Fig. 14. Embroidered wrapping cloth made from cotton \& silk, held in the Museum of Korean Embroidery.

From Huh, D. H. (1988). The wonder cloth. p. 181. cal expression by the vivid color contrast within the same plane. For example, the flying cranes in <Fig. 16> shows the color partitions within one motif. This kind of color arrangement was very similar to the saekdong, which was a method of putting different color strips together. Saekdong was one of the most popular decorations applied to many dress items, especially to children's jackets and coat sleeves.

Embroidered wrapping cloths revealed a clearer idea of why women made them through the motifs. The designer's wishes for happiness, longevity, and many sons can be read through the embroidered auspicious motifs. In the subo shown in 〈Fig. 16〉, she picked a tree, a flower, birds, butterflies, and bats.

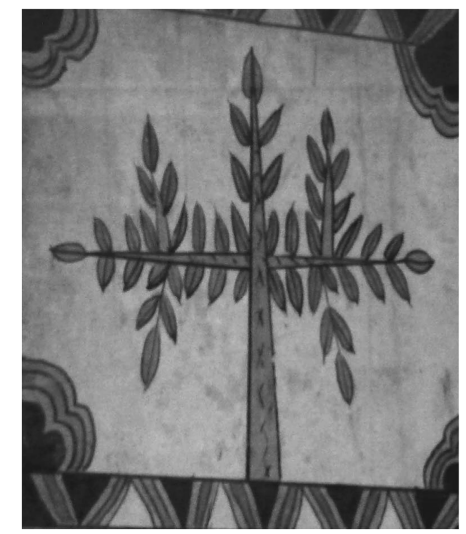

Fig. 15. Eight-panel Munjado screen, held in the British Museum.

Photographed by author (Feb. 24, 2009.)

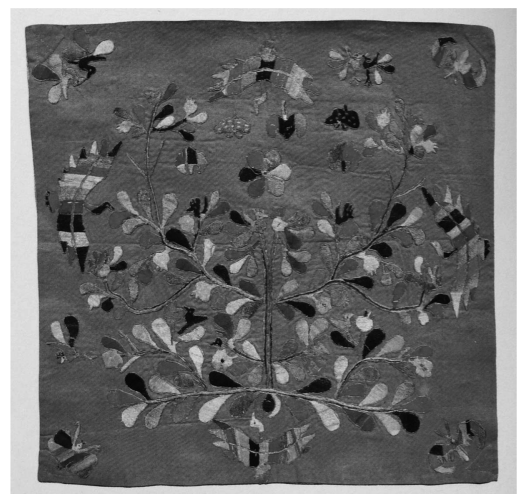

Fig. 16. Embroidered wrapping cloth, held in the Museum of Korean Embroidery.

From Huh, D. H. (2001). The world of colorful delight. p. 66. 
Trees have had sacred symbolism from the earliest times and the Koreans believed that the sacred tree connected heaven and earth; flowers symbolized wealth, prosperity, and honor (Huh, 1988; Kim, 2003). Along with trees, birds also symbolized the agents leading the human body and spirit to heaven. Cranes represented the scholar and longevity. Butterflies were frequently used to represent joy, happiness, conjugal harmony, and good luck. Bats were used as symbols of happiness and many sons (Dictionary of Korean myths and symbols, 2006).

Plant motifs such as trees and flowers also might have been suitable for female tastes. The rhythmical expression of these motifs through vivid color contrasts expressed the 'wholesome femininity' of Korean women.

\section{Characteristics of Painted, Printed, and Oiled-paper Wrapping Cloths}

\section{Painted Wrapping Cloths}

Compared to patch work wrapping cloths and embroidered wrapping cloths, a small number of the rest types of bojagi remain. However, the rest types are also worth examining given the variety of decorative techniques. Depending on the coloring technique, painted wrapping cloths were categorized into three types; 'deep shade Chinese-colors' wrapping cloths, 'light shade Chinese-colors' wrapping cloths, and 'black ink' painted wrapping cloths.

The Chinese-colors (dangchae) refer to a painting technique applied to wooden architecture, wall, pottery, paper, and cloth. The coloring material of dangchae was made from the natural mineral pigments. Most of dangchae wrapping cloths were made and used in the royal court. Some of them were also used by the aristocracy and by Buddhist temples (Kim, 1998). The difference between two types of the Chinese-colors was from the pigment concentration. If the concentration was too high, the pigment was easily cracked. On the other hand, if the concentration was too low, the color was not as clear as needed (Kim, 1998). Because of the mineral pigment, dangchae tends to be so durable that we can see nearly the original shade of vivid color expressions.

As with the embroidered wrapping cloths, the painted cloth had an exuberant array of auspicious symbols for its decorative theme. The painted cloth shown in <Fig. 17> is an example of a 'light shade Chinesecolors' type. The central circular bands are contained in a square that is surrounded by smaller squares that contains interlocking shapes, yin-yang symbols, and swastikas. These are surrounded in turn by an outer row of squares containing flower heads, and a band of brown yin-yang symbols on the outer edges (McKillop, 1992). Dangchae wrapping cloths were made from ramie, hemp, and cotton as it was probably easier to draw on stiff vegetable fibers rather than on soft animal fibers.

Not like dangchae wrapping cloths, black ink painted wrapping cloths are thought to have been used by commoners (Kim, 1998). Bojagi shown in $<$ Fig. 18> is one example of black ink painted wrapping cloths. The whole patterns were partitioned into sixteen of the same-sized squares. Each section was filled with the auspicious motifs having symbolic meanings. For example, crane, turtle, deer, and immortal plants symbolize longevity. Fish and peony represent abundance. Lotus and grapes are the icons of many sons. Tigers represent braveness. Phoenix symbolizes the pleasures of married life and the status of the king or queen (Kang, 1997). This kind of painted

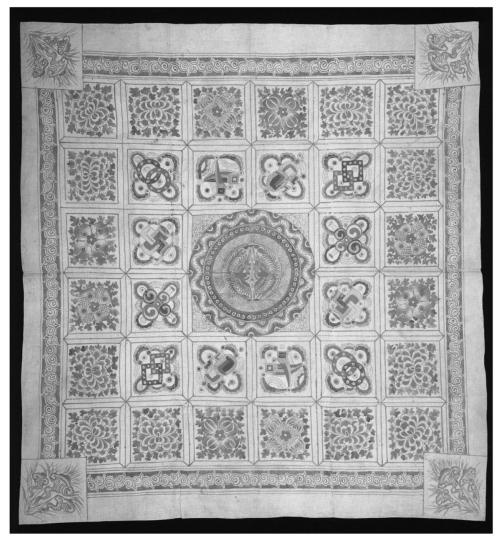

Fig. 17. Chinese-colors painted wrapping cloth made from hemp, held in the Victoria \& Albert Museum.

From McKillop, B. (1992). Korean art and design. p. 145. 


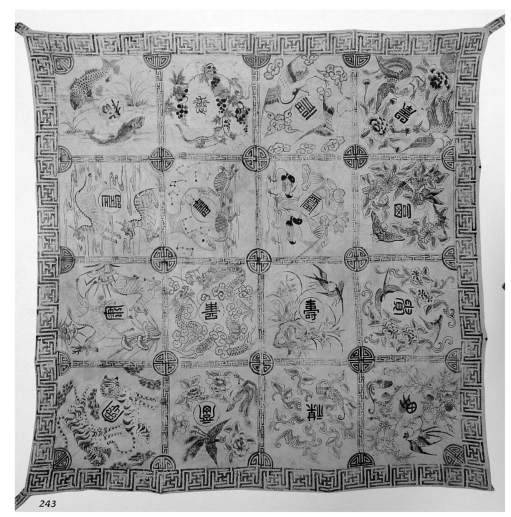

Fig. 18. Black ink painted wrapping cloth, held in the Museum of Korean Embroidery.

From Huh, D. H. (1988). The wonder cloth. p. 248.

cloth was called a baikrakbo, which means a wrapping cloth for a hundred pleasures (Huh, 1988). A very similar style of painting (partitioned into sixteen sections and depicting auspicious animals and flowers in each section) was also found in the Chinesecolors wrapping cloths made from cotton (Huh, 1988). In light of this, it is inferred that this kind of style was one of the typical designs painted on wrapping cloths.

It seems likely that the painting decoration was rarely in use for Korean dresses worn in the Joseon dynasty. However, the painting techniques and styles shown in wrapping cloths imply that the inhabitants of the Joseon dynasty had a tradition of painting decorations on fabric materials.

\section{Printed Wrapping Cloths}

Printed wrapping cloths were decorated with a printing technique instead of painting. Many woodblocks used for printing work have been preserved in museums (Huh, 1988; Sim, 2002; The National Research Institute of Cultural Properties, 1999). Some of the woodblocks were engraved with small-sized single pattern, most of which represented flowers, animals, and Chinese characters. Others had a bigger-sized repetitive pattern that was intended to make successive patterns when printed repeatedly. One of remaining woodblocks was engraved with geometric lattice patterns, a pair of cranes, butterflies, and a chrysanthemum (Huh, 1988). One of them was also engraved with a bat motif within a round shape (Sim, 2002). The wrapping cloth shown in <Fig. 19> was probably printed using one of these woodblocks.

There was also a cylinder shape of wooden roller made in the $17^{\text {th }}$ century Joseon dynasty (Huh, 1988). It is believed that block-printing was developed as one of the labor-saving methods because painting (pen-work) was time-consuming work. Block-printing was used by European textile printers until the early $20^{\text {th }}$ century. It was gradually superseded by the invention of speedier methods such as roller printing (Burnard, 1994). It is meaningful that Joseon era printers applied a roller principle to printing as early as the $17^{\text {th }}$ century.

The inhabitants of the Joseon dynasty rarely applied a printing technique to fabric materials for dresses, except gold or silver printing, however, monotone woodblock printing similar to <Fig. 19> was also found in other fabric items. A cotton pouch made in the $19^{\text {th }}$ century represented a printed lozenge pattern (Sim, 2002). In a set of helmet and armor worn in Joseon dynasty, the similar printing technique depicting repetitive swastikas motifs was also found (Fig. 20).

$<$ Fig. 21> is the part of the printed wrapping cloths made from cotton called chintz. This kind of printed cotton was called in Korean a hwapo (flower fabric) (Sim, 2002). Chintz refers to cotton fabric of floral patterns that would be stained with fast colors by the process of painting and printing (Irwin \& Brett, 1970). A chintz was made in India for the European market

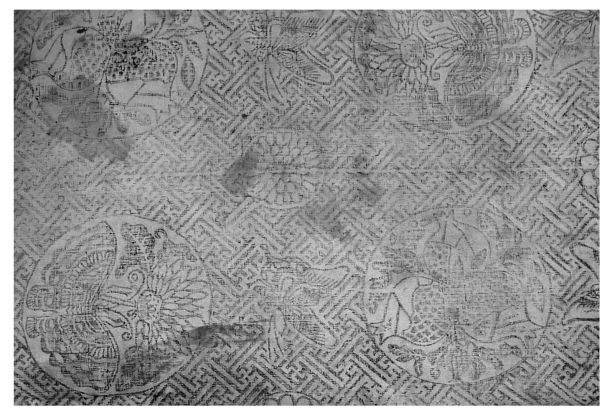

Fig. 19. Printed wrapping cloth (part), held in the Museum of Korean Embroidery.

From Huh, D. H. (1988). The wonder cloth. p. 247. 


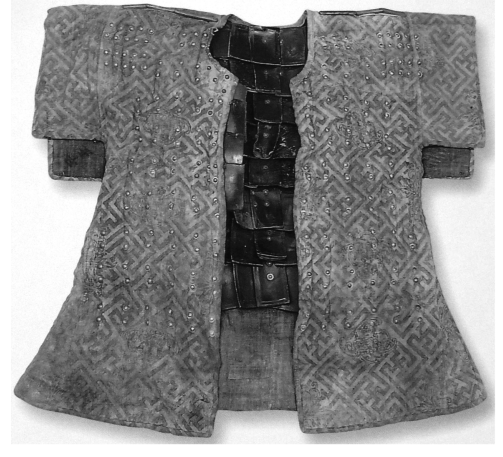

Fig. 20. Armor.

From The National Research Institute of Cultural Properties. (1999). Korean cultural properties of the Guimet national museum of Asian art, France. p. 63.

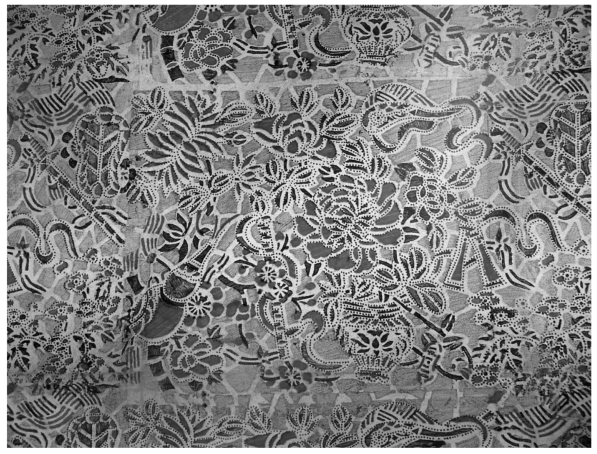

Fig. 21. Printed wrapping cloth (part) made from cotton (chintz), held in the Museum of Korean Embroidery.

From Huh, D. H. (1988). The wonder cloth. p. 242.

and was very popular in $18^{\text {th }}$ and $19^{\text {th }}$ century Europe. It was also traded among some countries, including Cambodia, Thailand, China, and later to Japan through the Dutch (Burnard, 1994). It is meaningful that chintz fabric was in use for Korean wrapping cloths (Sim, 2002). Chintz was not applied to materials for Korean dresses as much as Western or Japanese dresses. However, given the remaining chintz wrapping cloths and the name of Joseon chintz written in a Japanese document called ${ }^{『} J e u n g b o$ Hwapo Pyeonram』(as cited in Sim, 2002), some of Joseon printers might have known the decorative technique of chintz and reproduced it.

Thin gold paper called geumbak or silver paper called eunbak, was sometimes printed on the wrapping cloths (Huh, 1988). Geumbak or eunbak was one of the most popular decorations applied to many kinds of Korean dresses, including jacket shoulders, skirt hemlines, and hair-dresses.

\section{Oiled-paper Wrapping Cloths}

Oiled-paper wrapping cloths called sikjibo are known to have been used only for covering food, because food spoilage could be prevented by using oiled-paper. The cut-out work of the colored-paper was mainly employed for decorating oiled-paper wrapping cloths. Chrysanthemum, bats, and butterflies were the most popular motifs (Fig. 22). Sometimes, patchwork wrapping cloths were lined with oiled-paper for practical reason (Huh, 1988).

In the late Joseon dynasty, increased production of various colored-papers led to the development of colored-paper decorated boxes. These boxes were used as thread boxes, sewing boxes, thimble cases, and make-up boxes. Most of the remaining decorative boxes were made from wooden material first and then covered with patterned colored-paper that represented the symmetrical shapes of triangles, squares, and circles (The National Research Institute of Cultural Properties, 1999). Besides the geometric patterns, there were also other types of patterns such as flowers and Chinese characters (Huh \& Park, 1988). One of the handicraft frames of colored-paper is preserved in the Guimet National Museum of Asian Art (Fig. 23). From this example, it is inferred that the

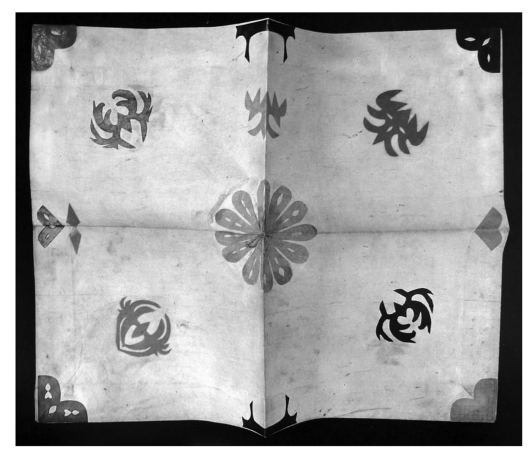

Fig. 22. Oiled paper wrapping cloth, held in the Museum of Korean Embroidery.

From Huh, D. H. (1988). The wonder cloth. p. 133. 


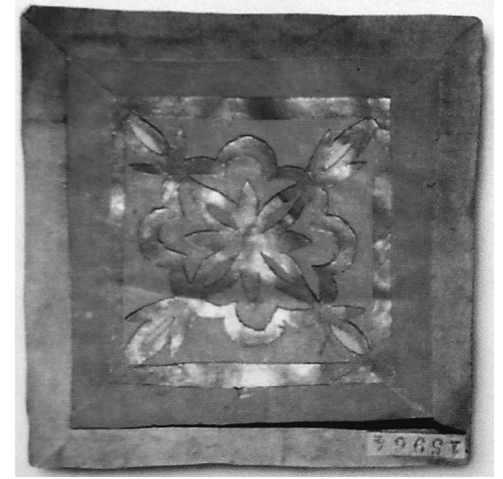

Fig. 23. Colored-paper handicraft frame.

From The National Research Institute of Cultural Properties. (1999). Korean cultural properties of the Guimet national museum of Asian art, France. p. 307.

basic patterns of frames were in use for the cut-out work. This is probably why similar shapes of motifs such as bats, flowers, and butterflies are shown in some oiled-paper wrapping cloths. The principle of the cut-out work seems similar to the stencil dyeing technique. The motifs and colors from the oiled-paper wrapping cloths could be applied to the decoration of fabric materials through the use of a stencil dyeing technique.

\section{Conclusions}

This paper explored the reasons why Korean wrapping cloths were made and used in the late Joseon dynasty, and what types of decorations were applied to the wrapping cloths. Three aspects were examined with regard to the reasons for the making of bojagi. The first reason was related to the practical aspect such as everyday usage and the saving of materials. The second one was connected to the down-to-earth wishes of the designer. The final was related to the satisfaction of creation and the expression of feeling.

The five types of decorative features of Korean wrapping cloths including patchwork, embroidered, painted, printed, and oiled-paper wrapping cloths were examined. Patchwork wrapping cloths, jogakbo, were the most typical type of Korean wrapping cloth. According to the method of arrangement of lines and colors, it was subdivided into three types; the compo- sition of regular shapes and various colors, the composition of irregular shapes and monochrome color, and the composition of irregular shapes and various colors. The remaining embroidered wrapping cloths called subo were most often made and used by the inhabitants of Gangwon province. This subo was prepared for auspicious ceremonies such as weddings. The subo represented several features in relation to the expression of embroidery motifs. The motifs were simplified and the whole shape had a combined viewpoint. The surface was compacted with embroidered motifs and each part of the motif was expressed through a vivid color contrast.

Compared to patchwork and embroidered wrapping cloths, the rest of the types of wrapping cloths remained on a small scale. However, given the variety of decorative techniques, the rest types also deserve attention. Depending on the coloring technique, painted wrapping cloths were categorized into three types; 'deep shade Chinese-colors' wrapping cloths, 'light shade Chinese-colors' wrapping cloths and 'black ink' painted wrapping cloths. Printed wrapping cloths were decorated with a printing technique instead of painting. The inhabitants of the Joseon dynasty rarely applied printing techniques to dress items, except gold or silver printings. However, woodblock printing was employed for some wrapping cloths and other fabric items such as a pouch, a set of helmet and armor. In addition, some of Joseon printers used the decorative technique normally as shown in chintz, having various colors of floral patterns. Oiled-paper wrapping cloths called sikjibo were in use only for covering food. Cut-out work was mainly employed to decorate it. The principle of the cut-out work appears similar to stencil dyeing technique.

Tradition has an intrinsic value when it is well positioned within the present context and succeeded by the future generations. The Korean wrapping cloths explored in this paper show various decorative techniques applied to fabric materials, which were rarely found in Korean dress objects. It will be meaningful if these decorative factors were applied to contemporary textile and dress designs. For this purpose, it would be important to find lost decorative techniques 
(especially in the field of painting and printing crafts) as well as to research and develop traditional coloring materials.

\section{References}

Berliner, N. Z. (1986). Chinese folk art. Boston: Little, Brown and Company.

Burnard, J. (1994). Chintz and cotton. Kenthurst: Kangaroo Press.

Dictionary of Korean myths and symbols. (2006). Seoul: Doosan Donga.

Gilfoy, P. S. (1987). Patterns of life. Washington, DC: Smithsonian Institution Press.

Huh, D. H. (1988). The wonder cloth. Seoul: The Museum of Korean Embroidery.

Huh, D. H. (2001). The world of colorful delight. Seoul: The Museum of Korean Embroidery.

Huh, D. H. (2003). History and art in traditional wrapping cloths. In J. M. White \& D. H. Huh (Eds.), Wrapping of happiness (pp. 20-24). Hawaii: Honolulu Academy of Arts.

Huh, D. H., \& Park, Y. S. (1988). Crafts of the inner court. Seoul: The Museum of Korean Embroidery.

Hyen, S. J. (1997). A study on the woman's artistic consciousness in Chosun dynasty. Unpublished master's dissertation, Chonnam National University, Gwangju.

Irwin, J., \& Brett, K. (1970). Origins of chintz. London: H. M. O. S.

Kang, J. C. (1997). A study on the symbols of the folks appeared in the passing rituals. Danguk University Kukmunhak Nonchong, 15, 53-107.

Kim, H. N. (2007). A study on the color harmony for development of cultural goods. Unpublished master's dissertation, Hongik University, Seoul.

Kim, K. P. (2003). Profusion of color. In J. M. White \& D. H. Huh (Eds.), Wrapping of happiness (pp. 10-19). Hawaii: Honolulu Academy of Arts.

Kim, O. K. (1998). Study on the expressional techniques in Yi-dynasty's Pojagi. Hanguk Gongye Nonchong, 1, 6186.

Kim, S. Y. (2005). The associational meaning of purple- serious color names in the clothing of Joseon dynasty period. Journal of the Korean Society of Costume, 55(3), 1-18.

Kim, S. D. (1997). Joseon Jaebong Jeonseo (Joseon Sewing Encyclopedia) (Minsokwon, Reprint). Seoul: Minsokwon. (Original work published 1925)

King Seongjong. (1985). Geongguk Daejeon (The National Code of Joseon dynasty) (Hanguk Jeongsin Munhwa Yeonguwon, Reprint). Seongnam: Hanguk Jeongsin Munhwa Yeonguwon. (Original work published 1485)

Korea Culture and Content Agency, Jds infotech, Ltd, \& Chungang University. (2004). Kisan Pungsokdo Digital Hwacheop (Digital Catalogue of the Folk Paintings by Kisan). Culture Content. Retrieved February 1, 2009, from http://kisan.culturecontent.com

Lee, K. E. (2003). Wrapping cloths and the life of women in the late period of Joseon dynasty focusing on patchwork wrapping cloth. Unpublished master's dissertation, Ewha Womans University, Seoul.

Lee, K. S. (1999). Korean wrapping clothes. Hongik Faculty Journal, 31, 3-18.

McKillop, B. (1992). Korean art and design. London: Victoria \& Albert Museum.

National Museum of History. (2000). Costumes and accessories of Chinese minorities. Taibei: National Museum of History.

National Museum of Korea. (1988). Hangukui Mi (Beauty of Korea). Seoul: National Museum of Korea.

Noh, E. H. (2006). A measurement study on color distribution and combination of bojagi in Joseon period. Unpublished doctoral dissertation, Hongik University, Seoul.

Sim, Y. O. (2002). 5000 years of Korean textiles. Seoul: Institute for Studies of Ancient Textiles.

The National Research Institute of Cultural Properties. (1999). Korean cultural properties of the Guimet national museum of Asian art, France. Seoul: The National Research Institute of Cultural Properties.

Yi, N. H. (1986). Joseon Yeosokko (Joseon women's customs) (Minsokwon, Reprint). Seoul: Minsokwon. (Original work published 1927)

Yi, S. M. (2003). Women in Korean history and art. In J. M. White \& D. H. Huh (Eds.), Wrapping of happiness (pp. 25-37). Hawaii: Honolulu Academy of Arts.

\section{요 약}

이 논문은 조선후기 보자기에 적용된 다양한 장식 특성을 연구한 것이다. 보자기는 물건을 싸거나 음식 을 덮는 등 일차적으로는 실생활에 활용하기 위한 실용적 목적으로 제작되었지만, 보자기 제작은 전래된 상징적 문양의 표현을 통한 현세적 기원의 행위이기도 했으며, 또한 조선의 엄격한 유교 윤리 하에서 여 
성의 창작 욕구가 자유롭게 발현된 생활 속 여흥의 일부이기도 했다. 한국의 보자기에는 조각 잇기, 자수, 회염, 인염, 오려내기 세공 등 다양한 장식 기법이 활용되었다. 조각 잇기 기법이 활용된 조각보에서는 조 선 여인들의 절약습관이 돋보이는데 이는 특히 자원의 재활용을 중시하는 오늘날의 가치와도 일맥상통하 는 바가 있다. 자수가 놓인 수보에서는 상징적 문양의 표현을 통한 여인들의 소박한 바램이 읽혀진다. 한 국 보자기는 회염이나 인염으로 장식되기도 했는데, 이들은 한국 복식 유물에서는 보기 어려운 장식 기법 들이다. 농담을 조절한 다양한 색채의 당채 기법이나 단일색의 먹물 채색, 여러 종류의 도안이 새겨진 목 판을 이용한 인염 기법 등이 이용되었다. 음식물이 묻지 않게 하기 위해 때로는 기름 종이로 보자기를 만 들기도 했는데, 이러한 식지보에는 오려내기 세공이 장식 기법으로 활용되었다. 오려내기 기법의 원리는 스텐실 염색과 비슷하여 이를 또한 섬유제품 디자인에 활용할 수도 있다. 